\title{
Rancang Bangun Sistem Monitoring Cryptocurrency Secara Real Time Menggunakan Arduino
}

\author{
Edy Suwasono $^{1}$, Septi Andryana ${ }^{2}$, Rini Nuraini ${ }^{3}$ \\ ${ }^{1,2,3}$ Program Studi Teknik Informatika, Fakultas Teknologi Komunikasi dan Informatika \\ Universitas Nasional, Jl. Sawo Manila, Pejaten Ps. Minggu Jakarta 12520 \\ e-mail: ${ }^{1}$ edysuwaono@gmail.com, ${ }^{2}$ septi.andryana@ civitas.unas.ac.id, \\ rini.nuraini@civitas.unas.ac.id
}

\begin{abstract}
Abstrak
Cryptocurrency adalah sebuah teknologi berbasis blockchain yang sering digunakan pada saat ini sebagai mata uang digital. Bentuk cryptocurrency di minati oleh masyarakat karena pengelolaannya yang terdesentraliasi, proses yang mudah, serta memungkinkan transaksi tanpa perlu adanya perantara pihak ketiga. Teknologi Internet of Things (IoT) memiliki dampak penting pada pengembangan informasi yang didapatkan untuk memantau perubahan informasi secara langsung tanpa adanya interaksi dari pengguna ke perangkat komputer, seperti menampilkan stabilitas cryptocurrency terutama pada Bitcoin, Ethereum, dan Binance. Hasil dari rancangan sistem monitoring berhasil, data yang ditampilkan pada layar oled sesuai dengan sumber yang diacu yaitu memnunjukan harga mata uang bitcoin $\$ 39,436.76$, ethereum $\$ 2,505.10$, dan binance $\$ 1.54$ dengan menggunakan aplikasi ThingSpeak.com, Arduino IDE sebagai pemroses data, kemudian transfer data secara real time memanfaatkan ESP8266 dan layar oled.
\end{abstract}

Kata kunci-Cryptocurrency, Intenet of Things (IoT), Arduino, Informasi

\begin{abstract}
Cryptocurrency is a blockchain-based technology that is often used today as a digital currency. This form of cryptocurrency is of interest to the public because of its decentralized management, easy process, and allows transactions without the need for a third party intermediary. Internet of Things (IoT) technology has an important impact on the development of information obtained to monitor changes in information directly without any interaction from the user to the computer device, such as displaying the stability of cryptocurrencies, especially in Bitcoin, Ethereum, and Binance. The results of the monitoring system design were successful, the data displayed on the OLED screen according to the referenced source, namely showing the price of bitcoin $\$ 39,436.76$, ethereum $\$ 2,505.10$, and binance $\$ 1.54$ using the ThingSpeak.com application, Arduino IDE as a data processor, then real data transfer time utilizes ESP8266 and oled screen.
\end{abstract}

Keywords - Cryptocurrency, Intenet of Things (IoT), Arduino, Information.

\section{PENDAHULUAN}

$P_{n}^{\mathrm{e}}$ erkembangan teknologi dan informasi sudah sangatlah pesat. Keberadaan internet tealah menyediakan akses secara mudah untuk menemukan informasi [1]. Namun, sumber informasi di internet cukup bervariasi. Oleh karena itu, mencari informasi memerlukan kajian 
khususnya dibidang keuangan, yang dimana pada saat ini dengan adanya cryptocurrency sebagai aset mata uang digital menjadi wadah sarana transaksi elektronik secara otomatis [2]. Maka harga mata uang digital semakin meningkat, sehingga membuat semua orang berlombalomba dalam menambang bitcoin, etherum, dan binance yaitu merupakan contoh jenis mata uang digital cryptocurrency yang biasa digunakan oleh negara - negara maju.

Teknologi banyak memberikan akses untuk mendapatkan informasi semakin mudah. Namun sayangnya, tidak semua beredar di internet merupakan informasi yang akurat. Dalam menemukan informasi spesifik menggunakan mesin pencari google dari sumber - sumber yang ada tidaklah selalu dianjurkan [3]. Oleh karena itu, kebijakan dalam memilah dan memilih informasi sangat penting. Terlebih untuk para pengguna cryptocurrency, dengan informasi secara real time dan data yang akurat maka akan membantu dalam memonitoring.

Dalam mendapatkan informasi secara real time ada banyak cara salah satunya dengan pemanfaatan alat mikrokontroler arduino dan keunggulan Internet of Things (IoT) memberikan perubahan secara langsung informasi tanpa adanya interaksi dari pengguna ke perangkat komputer [4]. Contohnya mengenai data stabilitas Bitcoin, Ethereum, dan Binance perlu diketahui dari mana memperoleh informasi data maupun pendekatannya melalui cara analisis fundamental yang digunakan oleh pengguna untuk menentukan "nilai intrinsik" suatu aset dan menyelidiki berbagai faktor internal dan eksternal dengan tujuan utama untuk menentukan apakah aset cryptocurrency dianggap sangat tinggi atau sangat rendah. kemudian dapat menggunakan informasi tersebut untuk masuk atau keluar posisi secara strategis. Dengan pembuatan sistem monitoring ini beroperasi dalam beberapa tahapan dan kemudian mempengaruhi proses pendataan dan data yang dihasilkan [5]. Menarik dari situs web atau API yang berfungsi untuk menginformasikan data cryptocurrency mata uang bitcoin, ethereum, dan binace serta penggunaan alat yang telah di uji coba untuk menampilkan data secara real time [6].

Kajian - kajian pada penelitian yang berhubungan dengan pembahasan ini dapat dijadikan sebagai bahan acuan. Penggunaan alat mikrokontroler arduino digunakan sebagai sarana untuk menampilkan hasil data secara real time juga diterapkan pada "sistem peringatan dini banjir alat untuk memonitoring data banjir menggunakan Google Maps dirancang menggunakan perangkat sensor ketinggian air yaitu ultrasonik, untuk pengolah menggunakan Arduino Uno, modul GPS U-Blox Neo 6m dan modul GSM untuk mengirimkan data volume ketinggian air dan sistem pusat terjadinya banjir. Rangkaian prototype memberikan data peringatan banjir dan tempat terjadinya banjir mengacu pada Google Maps" [1].

Berdasarkan dari penelitian - penelitian sebelumnya, dapat dilakukan pengembangan penelitian kombinasi alat mikrokontroler. Arduino dan system Internet of Thing (IoT). Perancangan sistem monitoring ini dibuat menggunakan perangkat lunak Arduino IDE, ThingSpeak.com, serta perangkat keras menggunakan kabel jumper, mikrokontroler Arduino ESP82666, dan OLED.

\section{METODE PENELITIAN}

\subsection{Analisis Kebutuhan Sistem}

Tahap in dilakukan dengan bagian menganalisis bagian kebutuhan sistem, menganalisis perangkat keras, dan menganalisis perangkat lunak. 


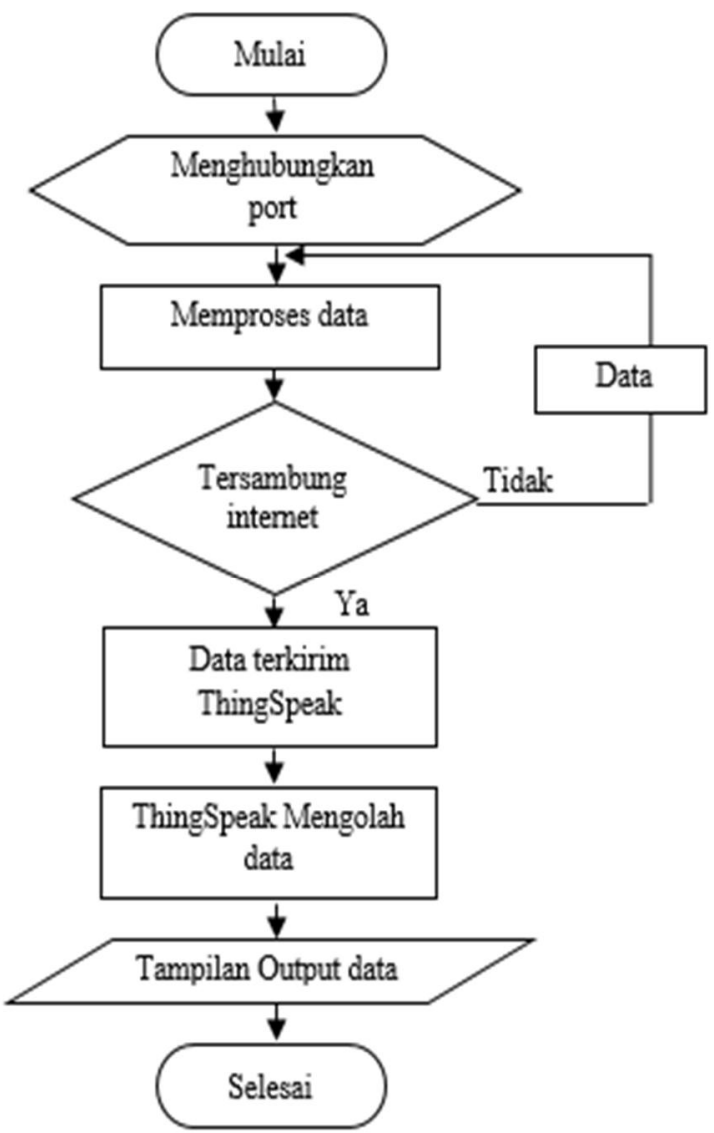

Gambar 1. Flowchart Sistem Monitoring

Dalam mengawali tahap penelitian dengan membuat rancangan sistem serta pemilihan alat untuk diimplementasikan yaitu dengan merancangan prototype perangkat keras, pemrosesan sensor, pemrosesan monitor, dan menjalankan percobaan [7]. Skema Flowchart pada sistem monitoring pada Gambar 1, menjelaskan tentang bagan tahapan program dari data yang dibutuhkan oleh sistem, proses data, hingga hasil data yang ditampilkan selesai pada sistem monitoring cryptocurrency.

\subsection{Analisis Perangkat Keras}

Langkah penelitian ini dilakukan dengan perancangan alat dan memilih komponen yang diperlukan. Berikut adalah komponen yang akan di implementasikan pada rangkaian sistem monitoring beserta fungsinya:

Tabel 1. Bagian Perangkat Keras dan Fungsinya

\begin{tabular}{|c|c|c|}
\hline No & Komponen & Fungsi \\
\hline 1. & Layar Oled 1.3 & $\begin{array}{l}\text { Menampilkan informasi data } \\
\text { yang dikirimkan oleh } \\
\text { NodeMCU }\end{array}$ \\
\hline 2. & Breadboard & $\begin{array}{l}\text { Papan penghubung antar } \\
\text { perangkat }\end{array}$ \\
\hline 3. & Kabel jamper & $\begin{array}{l}\text { Penghubung antara } \\
\text { NodeMCU dengan Oled } 1.3\end{array}$ \\
\hline
\end{tabular}




\begin{tabular}{lll} 
4. & $\begin{array}{l}\text { Esp8266 } \\
\text { (wireless) }\end{array}$ & $\begin{array}{l}\text { Mengirim dan mengolah data } \\
\text { 5. }\end{array}$ \\
Kabel USB & $\begin{array}{l}\text { Menghubungkan NodeMCU } \\
\text { ke laptop untuk diberikan } \\
\text { perintah atau program }\end{array}$ \\
\hline
\end{tabular}

\subsection{Analisis Perangkat Lunak}

Bagian dari sistem ini dioperasikan oleh mikrokontroler Arduino Esp8266 menggunakan bahasa pemograman $\mathrm{C}$, berikut ini merupakan beberapa perangkat lunak yang digunakan yaitu: 1. Arduino IDE sebagai program pengendali sistem

2. Website coinmarketcap digunakan untuk mengabil data cryptocurrency

3. Thingspeak gunanya untuk mengolah data melalui aplikasi berbasis web

\section{HASIL DAN PEMBAHASAN}

\subsection{Pemodelan Perangkat Keras}

Pada tahapan ini dimulai dengan merancang alat, pemilihan komponen yang perlu digunakan, dan membuat prototype perangkat keras sebelum membuat kode progam sistem kontrol sehingga dapat dilihat apakah program yang di buat dapat berjalan atau tidak. Selain Esp8266 ada bagian perangkat keras lainnya seperti Oled 1.3, Breadborad, kabel jamper, dan kabel USB di tunjukkan pada Gambar 2.

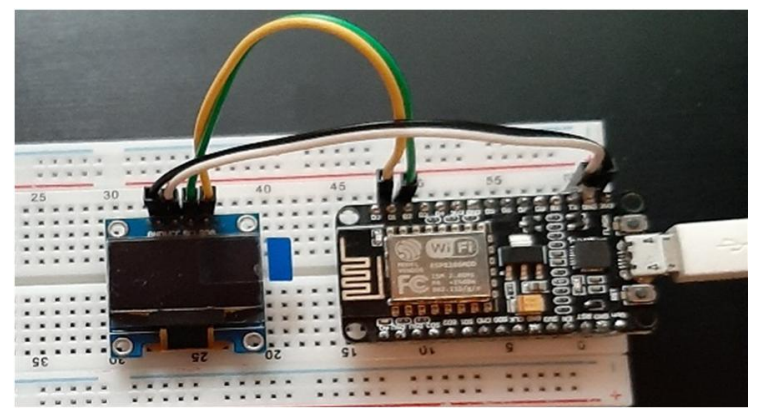

Gambar 2. Skema Rancangan Sistem Monitoring

Untuk merangkai alat sistem monitoring pertama yaitu jumper kabel warna hitam untuk disambungkan pada bagian 3v3 ESP8266 ke layar (VCC), setelah itu jumper kabel warna putih untuk dihubungkan pada ground ESP8266 ke layar (GND), lalu jumper kabel warna hijau (SCL) dan kuning (SDA) untuk input output kelayar dari ESP8266 D1 dan D2, kemudian hubungkan kabel USB kelaptop supaya terhubung dengan source code program. 


\subsection{Rangkaian Perangkat Lunak}

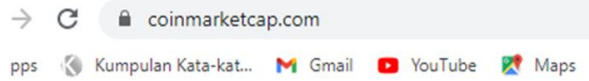

Gambar 3. Tampilan Web Coinmarketcap

Perangkat lunak adalah suatu aplikasi yang digunakan untuk mengontrol sistem agar alat tersebut dapat bekerja sesuai dengan kebutuhan, yaitu mengacu pada web coinmarketcap.com seperti pada Gambar 3 meliputi harga bitcoin, ethereum, dan binance dengan pengambilan data yang valid maka dapat dipastikan hasil data sesuai dengan yang diinginkan [8].

A thingspeak.com/apps/thinghttp/152217

Kumpulan Kata-kat... M Gmail - YouTube Maps

$\square$ ThingSpeak $^{\text {Tw }}$ Channels - Apps - Support-

Commercial Use How to Buy

Apps / ThingHTTP / BTC

\section{Edit ThingHTTP}

Name:

API Key: $\quad$ 3QAGQUBU1RV7SZU9

Regenerate API Key

URL: $\quad$ https://coinmarketcap.com/

HTTP Auth Username:

HTTP Auth Password:

Method: GET

Content Type:

HTTP Version: $\quad 1.1$

\section{Help}

You can now send your ThingHTTP request and view the response using the following URL:

GET https://api.thingspeak. com/apps/thinghttp/send_request?api_key=30AGO Learn More

Gambar 4. Tampilan Data pada ThingSpeak

Edy, et., al [Rancang Bangun Sistem Monitoring Cryptocurrency Secara Real Time Menggunakan Arduino] 
Thingspeak adalah aplikasi berbasis web untuk mengolah data dari coinmarketcap.com dikonversi kedalam bentuk API KEY seperti pada Gambar 4, selanjutnya API KEY tersebut dipergunakan didalam source code Arduino IDE agar data yang ditampilkan sesuai dengan sumber acuan $[9,10]$.

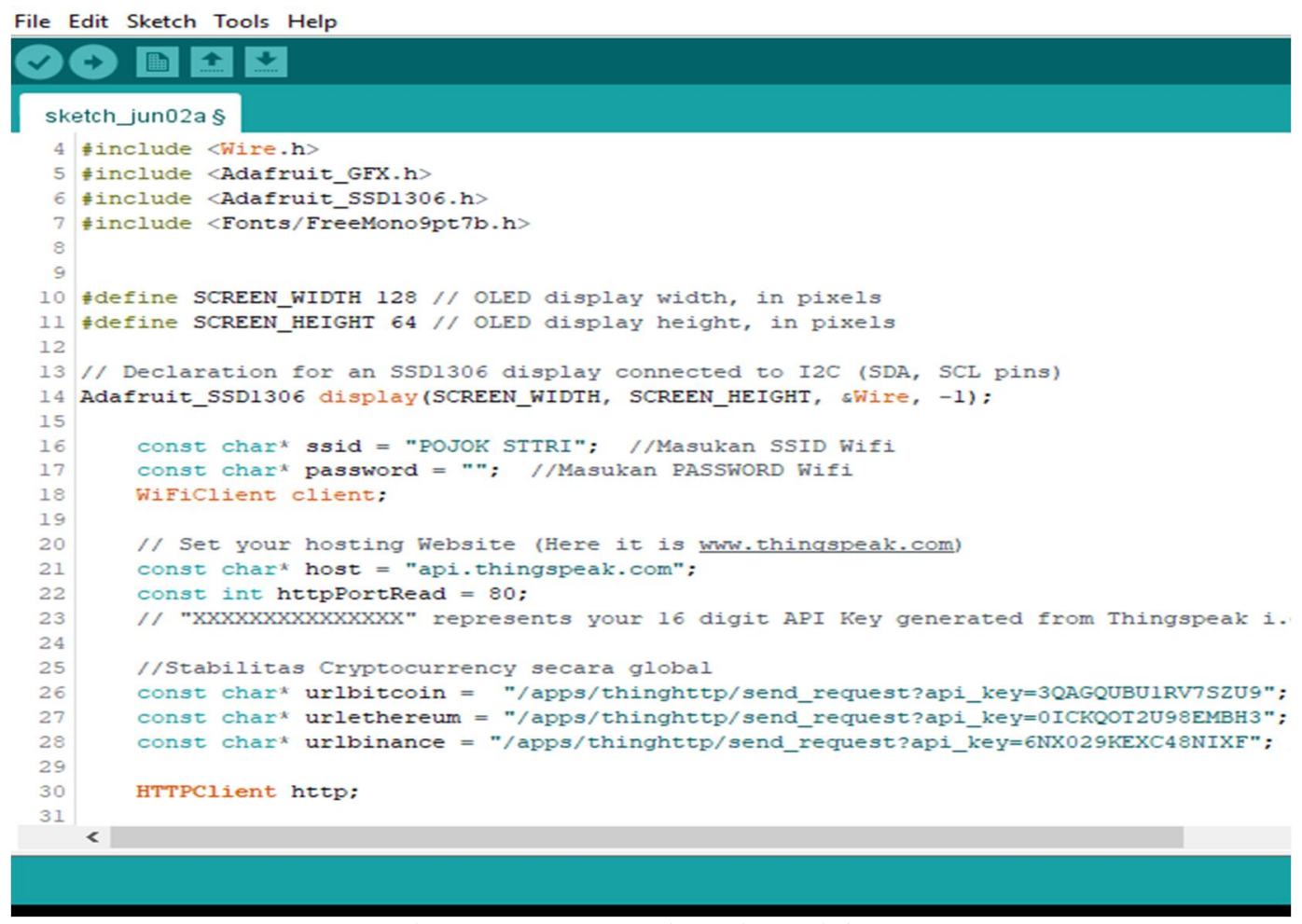

Gambar 5. Source Code pada Arduino IDE

Kemudian pada implementasi program melalui perangkat lunak Arduino IDE yang menggunakan bahasa $\mathrm{C}++$. Program disusun dengan penginstalan driver modul ESP8266 dan monitor layar oled seperti contoh pada Gambar 5 kemudian menerapkan data dari ThingSpeak ke perancangan program, selanjutnya data program tersebut akan dikirim ke modul Esp8266 sehingga dapat ditampilkan sebagai informasi secara fisik pada layar monitor oled. Untuk membuat suatu program sistem monitoring cryptocurrency perangkat lunak Arduino IDE berguna untuk memasukan source code program. Prosesnya dapat dijelaskan pada tampilan Gambar 6.

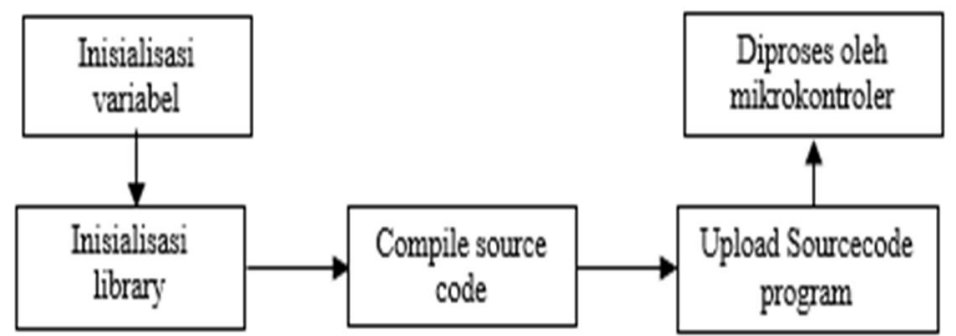

Gambar 6. Diagram Arduino IDE 


\subsection{Pengujian Alat}

Tahapa ini merupakan hasil dari pengujian sistem yang dilakukan bersamaan dengan pengembangan sistem yang dibangun terutama pada bagian implementasi perangkat keras yang terkait dalam sistem monitoring cryptocurrency. Pada langkah pengujian ini berguna untuk mengetahui kinerja alat yang digunakan.
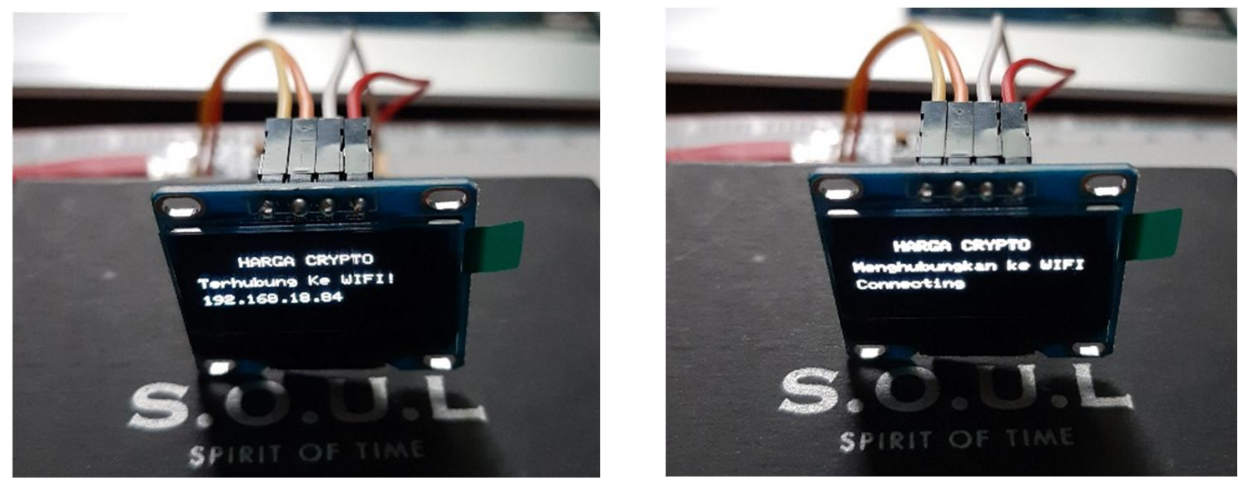

Gambar 7. Tampilan Sebelum dan Sesudah Terhubung ke Jaringan Wifi

Seperti pada Gambar 7 merupakan pengujian dari fungsi alat pada setiap konsep terutama tampilan output pada layar. Ketika ESP8266 terhubung ke internet maka akan ada tampilan IP address, tandanya sudah bisa menampilkan data. Jika tampilan layar hanya terdapat sampai connecting tandanya tidak terhubung ke internet, maka akan tampil input manual pada program dan tidak bisa menampilkan data berikutnya.

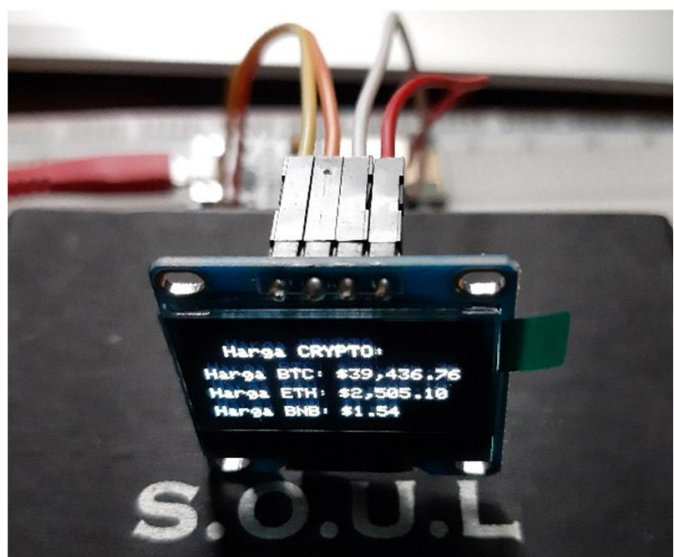

Gambar 8. Tampilan Data Aset Cryptocurrency

Informasi dapat diperoleh dari hasil pengujian prototype dan hasil aplikasi yang dirancang mengenai data stabilitas cryptocurrency yang di ambil dari sumber website coinmarketcap.com dan di tampilkan pada layar oled seperti pada Gambar 8 menampilkan informasi data harga bitcoin (BTC) $\$ 39,436.76$, ethereum (ETH) $\$ 2,505.10$, dan binance (BNB) \$1.54. Data yang dihasilkan bertindak sebagai kumpulan data untuk para pengguna memprediksi stabilitas cryptocurrency dengan caranya masing - masing pada setiap perubahan data. 


\section{KESIMPULAN}

Berlandaskan hasil percobaan serta analisis yang sudah dicoba sehingga dapat disimpulkan jika rancangan sistem monitoring cryptocurrency untuk memonitoring perubahan informasi mata uang bitcoin, ethereum, dan binance dengan teknologi Internet of Things (IoT) telah bekerja seperti yang diharapkan serta membantu para pengguna cryptocurrency dalam monitoring. Hal ini memiliki keuntungan bahwa perangkat yang digunakan lebih efisien dan menyimpan datanya telah memakai cloud. Serta, pengiriman data sudah berbasis Internet of Thigns (IoT) menggunakan ESP8266 yang berfungsi untuk mengolah data ke penyimpanan cloud secara real time dan hasil data akan ditampilkan dilayar oled sesuai dengan sumber.

\section{SARAN}

Saran untuk penelitian lanjutan yaitu untuk lebih meningkatkan dalam segi perangkat keras, serta mengembangkan pada sistem monitoring bisa lebih baik lagi, dan sistem lebih dikembangkan mengenai batasan masalah yang ada untuk pengembangan lebih lanjut supaya menghasilkan materi yang lebih luas.

\section{DAFTAR PUSTAKA}

[1] Satria, Dedi, et al. "Sistem Peringatan Dini Banjir Secara Real-Time Berbasis Web Menggunakan Arduino dan Ethernet." Jurnal JTIK (Jurnal Teknologi Informasi dan Komunikasi) 1.1 (2017): 1-6.

[2] Arief, Lathifah, and Tri A. Sundara. "Studi atas Pemanfaatan Blockchain bagi Internet of Things (IoT)." Jurnal RESTI (Rekayasa Sistem dan Teknologi Informasi) 1.1 (2017):70-75.

[3] Herlan, Agus, Iskandar Fitri, and Rini Nuraini. "Rancang Bangun Sistem Monitoring Data Sebaran Covid-19 Secara Real-Time menggunakan Arduino Berbasis Internet of Things (IoT)." Jurnal JTIK (Jurnal Teknologi Informasi dan Komunikasi) 5.2 (2021): 206-212.

[4] Prihatmoko, Dias. "Penerapan internet of things (IoT) Dalam Pembelajaran di UNISNU Jepara." Simetris: Jurnal Teknik Mesin, Elektro Dan Ilmu Komputer 7.2 (2016): 567-574.

[5] Budisanjaya, Putu Gede, and I. Wayan Tika. "Pemantau Suhu dan Kadar Air Kompos Berbasis Internet of Things (Iot) Dengan Arduino Mega dan Esp8266." Jurnal Ilmiah Teknologi Pertanian Agrotechno 1.2 (2016): 70-77.

[6] Sorongan, Erick, and Qory Hidayati. "ThingSpeak Sebagai Sistem Monitoring Tangki SPBU Berbasis Internet of Things." JTERA-Jurnal Teknologi Rekayasa 3.2 (2018): 219-224.

[7] Pambudi, Arif Setyo, Septi Andryana, and Aris Gunaryati. "Rancang bangun Penyiraman Tanaman Pintar Menggunakan Smartphone dan Mikrokontroler Arduino 
Berbasis Internet of Thing." Jurnal Media Informatika Budidarma 4.2 (2020): 250-256.

[8] Tukadi, Tukadi, et al. "Monitoring Pemakaian Daya Listrik Secara Realtime Berbasis Internet of Things." Prosiding Seminar Nasional Sains dan Teknologi Terapan. Vol. 1. No. 1. 2019.

[9] Adli, Fikri Faisal, and Ajib Setyo Arifin. "Sistem Monitoring Gas Co pada Parkiran Basement Mall di Jakarta Menggunakan Metode Real-Time Berbasis Internet of Things (IoT)." Jurnal Ilmiah Teknologi dan Rekayasa 24.3 (2020): 171-181.

[10] Sujadi, Harun, Tri Ferga Prasetyo, and Pafsi Paisal. "Pengembangan Sistem Monitoring Keamanan Sepeda Motor Berbasis Internet of Things." J-ENSITEC 5.01 (2018). 